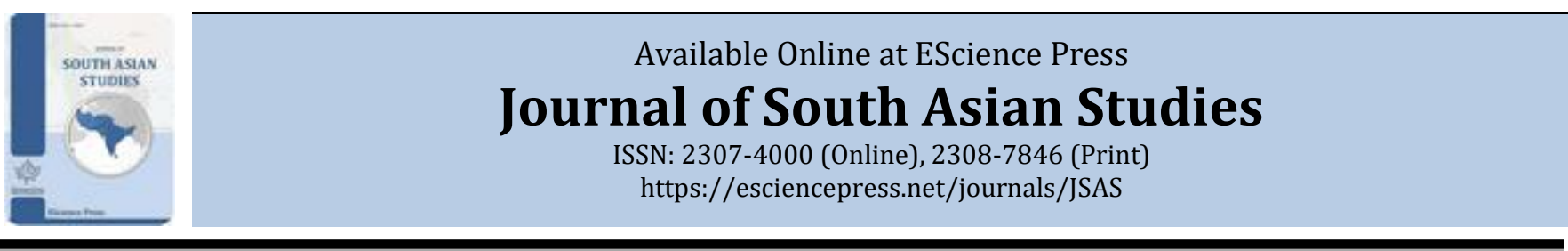

\title{
Socio-Industrial Impacts of CPEC on Pakistan: A Macro-Economic Study Within the Theoretical Context of Structural Anthropology
}

\author{
aTariq Saeed*, aDong Qian Li, bMuhammad Asim, cMuhammad Akram Zaheer \\ a School of Economics and Management, Changan University, Xian, China. \\ b Department of Political Science, Government Associate College (Boys) Dhoke, Syedan, Rawalpindi Cantonment, Pakistan. \\ c Department of International Relations, Informatics Group of Colleges Arifwala, Punjab, Pakistan.
}

*Corresponding Author Email ID: tariqsaeed55@yahoo.com

\section{A B S T R A C T}

Since the inauguration of CPEC as a plan to reconstruct the olden road between Kashgar and Gwadar, Pakistan is also experiencing socio-industrial impacts at the macro level. In fact, Chinese industries have built such a technical structure within the Pakistani markets that largely affects the nature of the masses. Likewise, socio-cultural life including the business environment in Pakistan has also been rapidly affected by the Chinese arrival. Therefore, by collecting primary sources from Pakistani and Chinese ministries regarding Chinese imports towards Pakistan; the study examines how it is encircling daily route life along with human nature. At the same time, consultation with different organizations and think tanks assists the study in practically investigating the socio-industrial impacts of CPEC within the theoretical context of structural anthropology in different regions of Pakistan.

Keywords: Khushka, Chinanization, Hanfu, Nichiren Buddhism, SMEDA, SIHEYUAN

\section{INTRODUCTION}

Industrialization always affects social life and human nature. However, the inauguration of CPEC is critically evaluated as the Chinanization of Pakistan for several years. As CPEC has installed such a socio-political structure in Pakistan that facilitates rapid change in human nature within the context of daily routine life (Zaheer, 2021), therefore, firstly this study looks at beginning of the association between Chinese industries and Pakistani customers that provides a basic ground to common people for change.

\section{BEGINNING OF ASSOCIATION BETWEEN CHINESE INDUSTRIES AND PAKISTANI CUSTOMERS}

The federal ministry of planning and development along with the CPEC authority in Pakistan has been starting their work on the association of Chinese industries with Pakistani markets (Zaheer, 2021). However, some facts have been published by both; Chinese government and the Pakistani government that indicate what is the actual worth of Chinese imports towards Pakistan, and how they have been associated with Pakistani customers.According to the "Trading Economics", during 2017 (as facts released by Chinese and Pakistani governments), Pakistan imported from China;

- Electrical and electronic equipment up to the worth of $\$ 3.39$ billion (Trading-Economics, Pakistan Imports from China, 2017).

- Nuclear reactors, machinery, and boilers up to the worth of \$3.39 billion (Trading-Economics, Pakistan Imports from China, 2017).

- Steel and Iron up to the worth of $\$ 1.18$ billion (Trading-Economics, Pakistan Imports from China, 2017). Manmade filaments up to the worth of $\$ 774.53$ million (Trading-Economics, Pakistan Imports from China, 2017).

- Organic chemicals up to the worth of $\$ 774.12$ (Trading-Economics, Pakistan Imports from China, 2017).

- Articles of steel and iron up to the worth of $\$ 755.22$ million (Trading-Economics, Pakistan Imports from 
China, 2017).

- Plastics up to the worth of $\$ 592.15 \mathrm{M}$ million (Trading-Economics, Pakistan Imports from China, 2017).

- Man-made staple fibers up to the worth of $\$ 576.74$ million (Trading-Economics, Pakistan Imports from China, 2017)

- Vehicles other than railway equipment up to the worth of $\$ 513.25$ million (Trading-Economics, Pakistan Imports from China, 2017)

- Fertilizers up to the worth of $\$ 421.27$ million (Trading-Economics, Pakistan Imports from China, 2017)

Pakistani Imports of Electrical and Electronic Equipment from China

There are a lot of Chinese electronics companies which are being export their products to Pakistan. Some of major Chinese electronics companies that export their electronic and electrical products to Pakistan are BOE, Haier, Changhong, Huawei, Hisense, Lenovo, Konka, Lenovo, Panda Electronics, SVA, Skyworth, TCL, Oppo, Xiaomi, ZTE, and DJI (Trading-Economics, Pakistan Imports from China of Electrical..., 2017).

All over Pakistan, electrical and electronic equipment manufactured by these companies are being used. However, there are a lot of markets located in Lahore, Islamabad, Rawalpindi, Peshawar, Multan, Bahawalpur, Faisalabad, Gujranwala, Gujrat, Karachi, Hyderabad, and Quetta where Pakistani traders import equipment from respective companies from China, and sale in the local market. Furthermore, all the respective markets are also linked with Pakistan Railways too (Trading-Economics, Pakistan Imports from China of Electrical..., 2017).

Pakistani Import of Nuclear Reactors, Machinery, and Boilers from China

According to the statistics, calculated in 2017, Pakistan imports from China;

- Steam or other kinds of vapor generating boilers $\mathrm{u}$ to the worth of $\$ 465.10$ million (Trading-Economics, Pakistan Imports from China of Machinery..., 2017).

- Air or Vacuum Pumps including other types of gas compressors up to the worth of $\$ 235.58$ million (Trading-Economics, Pakistan Imports from China of Machinery, 2017).

- Machinery for arranging, Sorting, categorizing, screening, transmitting, separating, washing, devastating, crushing, or mixing up to the worth of
$\$ 219.40$ million (Trading-Economics, Pakistan Imports from China of Machinery..., 2017).

- Apparatus for treatments of Materials by temperature up to the worth of $\$ 215.61$ million (Trading-Economics, Pakistan Imports from China of Machinery..., 2017).

- Steam turbines and their parts up to the worth of $\$ 153.50$ million (Trading-Economics, Pakistan Imports from China of Machinery..., 2017). Air conditioners up to the worth of $\$ 152.57$ million (Trading-Economics, Pakistan Imports from China of Machinery, 2017).

- Automatic data processing machines including optical or magnetic readers up to the worth $\$ 144.58$ million (Trading-Economics, Pakistan Imports from China of Machinery..., 2017).

- Mechanical and machines appliances having individual functions up to the worth of $\$ 120.33$ million (Trading-Economics, Pakistan Imports from China of Machinery..., 2017).

- Lifting or loading machines up to the worth of $\$ 111.90$ million (Trading-Economics, Pakistan Imports from China of Machinery..., 2017).

- Centrifuges (including filtering machinery) up to the worth of $\$ 103.18$ million (Trading-Economics, Pakistan Imports from China of Machinery..., 2017)

Except for centrifuges, all the machinery and boilers are being used all over Pakistan by local customers. However, only Pakistan Atomic Energy Commission imports centrifuges from China and uses them in the nuclear reactors near Chashma (Joharabad and Khushab), Dera Ghazi Khan, Chagai, Fateh Jang, and Kahuta. All the respective areas are also linked with Pakistan Railways except Kahuta whereas; Chagai is also linked with Pakistan Railways via Padag Road Railway Station (at Pak-Iran Railway Track) (Trading-Economics, Pakistan Imports from China of Machinery..., 2017)

\section{Pakistani Imports of Steel and Iron from China}

As China is producing 123 million tons of steel every year, it is examined that there are a lot of steel and iron companies existed in China (Trading-Economics, Pakistan Imports from China of Iron..., 2017). Some of them are; Angang Steel Company, Ansteel Group, Xinjiang Ba Yi Iron and Steel, Baoshan Iron and Steel Company, Baotou Steel, Wuhan Iron and Steel Corporation, Wuhan Iron and Steel Company, Beijing Shougang Company, Beiman Special Steel, Benxi Steel 
Group, China Baowu Steel Group, Chongqing Iron and Steel Company, Tianjin Pipe Corporation, Dongbei Special Steel, Fengbao Iron and Steel, Tiangong International, Fushun Special Steel, Tangsteel Group, Hansteel Group, Taiyuan Iron and Steel Group, Hesteel Group, Sinosteel, Huaigang Special Steel, Shougang Group, Hunan Valin Steel, Shougang Concord International, Jianlong Steel, Shaoguan Iron and Steel, Linzhou Steel, Shandong Steel, Maanshan Iron and Steel Company, Shagang Group, Magang Holding Company, Rolled Alloys, Meishan Iron and Steel, Nanjing Iron and Steel Company, Panzhihua Iron and Steel, Nanjing Iron and Steel Group, Vanadium Titanium and Resources, and, Pangang Group (Zaheer, 2021).

In Pakistan, the biggest users or importers of Chinese steel and iron have existed in Wazirabad, Gujrat, Lahore, Faisalabad, Gujranwala, and Sargodha. There are a lot of industries that need thousands of tons of steel every year whereas; they purchased steel from China at the lowest prices than the European or U.S market. Moreover, all the respective Pakistani cities are linked with Pakistan Railway while, the trading graph of steel would be higher if there will be functional Khunjerab Railway between Pakistan and China (TradingEconomics, Pakistan Imports from China of Iron..., 2017).

\section{Pakistani Import of Man-Made Fabrics from China}

Several Chinese cities like Suzhou, Wenzhou, Shanghai, Qingdao, Hangzhou, Jiaxing, Dongguan, and Weifang are famous for man-made fabrics. In all over Pakistan, Chinese man-made fabrics are being supplied whereas; trading graph of Chinese man-made fabrics towards Pakistan would be higher when Khunjerab Railway will connect Pakistan and China directly (Trading-Economics, Pakistan Imports from China of Manmade..., 2017).

2.5) Pakistani Imports of Organic Chemicals from China During 2017, it is investigated that Pakistan imports several organic chemicals from China like;

- Nitrile-function compounds up to the worth of $\$ 110.96$ million (Trading-Economics, Pakistan Imports from China of Organic..., 2017).

- Oxygen-functioning Amino-compounds up to the worth of $\$ 98.85$ million (Trading-Economics, Pakistan Imports from China of Organic..., 2017).

- Antibiotics up to the worth of $\$ 84.55$ million (Trading-Economics, Pakistan Imports from China of Organic..., 2017).

- Heterocyclic Compounds including nitrogen, Nucleic Acids (and their salts) up to the worth of $\$ 68.17$ million (Trading-Economics, Pakistan Imports from China of Organic..., 2017).

- Other heterocyclic compounds up to the worth of $\$ 62.81$ million (Trading-Economics, Pakistan Imports from China of Organic..., 2017).

- Compounds with other nitrogen functions up to the worth of $\$ 53.60$ million (Trading-Economics, Pakistan Imports from China of Organic..., 2017).

- Polycarboxylic acids (and their anhydrides), Halides, Peroxides (and their derivatives) up to the worth of \$30.59 million (Trading-Economics, Pakistan Imports from China of Organic..., 2017).

- Carboxylic Acids (with oxygen functions) along with their Anhydrides, Halides and Peroxides up to the worth of $\$ 30.04$ million (Trading-Economics, Pakistan Imports from China of Organic..., 2017).

- Provitamins and Vitamins up to the worth of $\$ 29.06$ million (Trading-Economics, Pakistan Imports from China of Organic..., 2017).

- Organo-sulfur compounds up to the worth of $\$ 25.95$ million (Trading-Economics, Pakistan Imports from China of Organic..., 2017).

- Moreover, there are a lot of companies that import respective organic chemicals from China. Some major companies among them are; Unitex Trading Corporation, Unity Group, Akbari International Corporation, Nippon Paint, FAV Group of Companies, Saudi Delta Company Pakistan, Mansoor Chemicals, Khyber Chemical Private limited, Chemco, Fuel Performance Catalyst, Humayun Wellchem Trading Concern, Suraj Fertilizer Industries Private Limited, National Gases Limited, Khawaja Mineral Industries Private Limited, Morgan Chemicals, Cosmo International, and 4 Brothers Group Pakistan (Trading-Economics, Pakistan Imports from China of Organic..., 2017).

Although this import process is occurred by airlines' services in case of establishing railway link between Pakistan and China, it is expected that this business can shift towards railway too (Trading-Economics, Pakistan Imports from China of Organic..., 2017).

\section{Pakistani Imports of Steel and Iron Articles from China}

In 2017, "Trading Economics" indicated that lots of steel and iron articles are being imported from China to Pakistan. These articles are;

- Structures (including parts of structures) up to the 
worth of $\$ 191.21$ million (Trading-Economics, Pakistan Imports from China of Iron..., 2017).

- Pipes, Tubes and Hollow Profiles up to the worth of \$84.64 million (Trading-Economics, Pakistan Imports from China of Iron..., 2017).

- Railway Track Construction Material up to the worth of \$29.92 million (Trading-Economics, Pakistan Imports from China of Iron..., 2017).

- Tube or pipe fittings up to the worth of $\$ 27.40$ million (Trading-Economics, Pakistan Imports from China of Iron..., 2017).

- Bolts, Screws, Nuts, Rivets Coach Screws and Screw Hocks up to the worth of $\$ 23.46$ million (TradingEconomics, Pakistan Imports from China of Iron..., 2017).

- Welded and Riveted pipes up to the worth of $\$ 18.09$ million (Trading-Economics, Pakistan Imports from China of Iron..., 2017).
- Stranded Wire, Cables, Ropes, Plaited Bands and Slings up to the worth of $\$ 15.70$ million (TradingEconomics, Pakistan Imports from China of Iron..., 2017).

- Chain and parts up to the worth of $\$ 13.95$ million (Trading-Economics, Pakistan Imports from China of Iron..., 2017).

Such imports are being consumed in all over Pakistan. There are several companies that import such articles of steel and iron from China. Moreover, in the case of railway connection between Pakistan and China, this trade will be converted at railway tracks instead of the current trade trend by roads and by air.

\section{Pakistani Import of Plastic from China}

According to Statistics Portal, China produced plastic products in respective million tons capacity during 2018 in December to December;

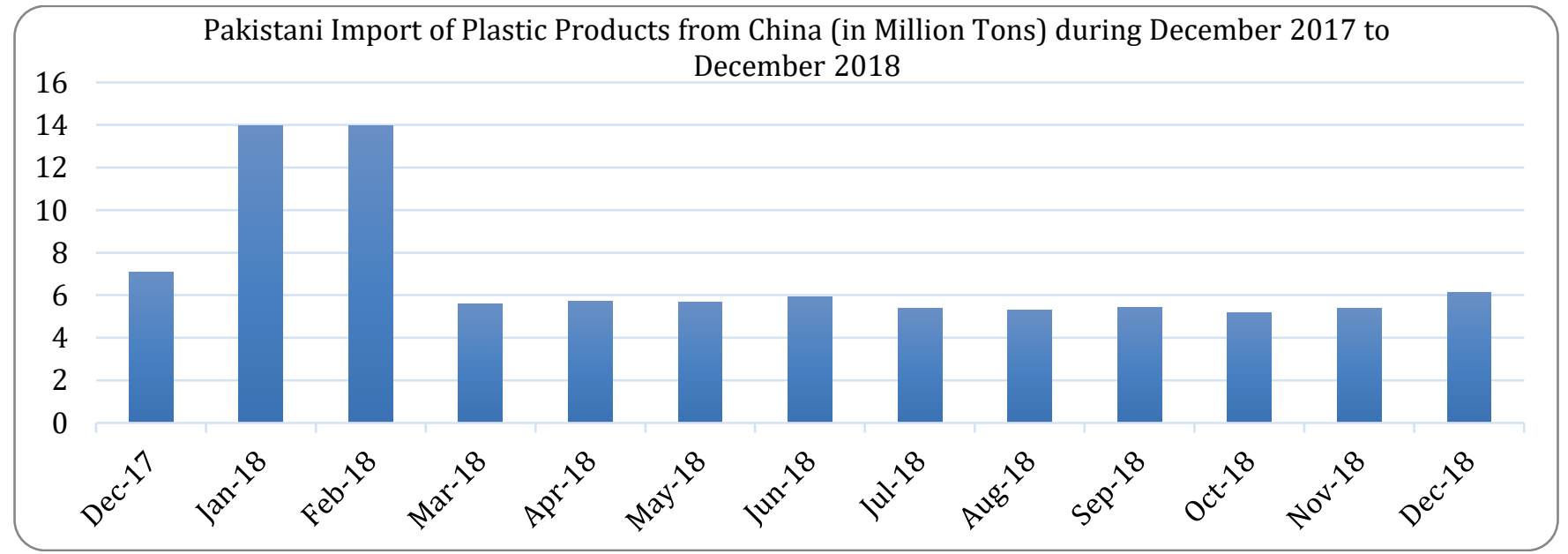

Figure1. Plastic Import from China.

Source: Chaudhry, 2018.

According to this chart, China produced highest capacity of plastic products in January and February 2018 where, the level of plastic products is up to 13.95 million ton while, this level reduced up to 6.12 million ton in
December 2018 (Chaudhry, 2018).Moreover, plastic industry has huge setup in all over Pakistan. The Chart given below shows the existence of different plastics units in all Pakistan;

Table 1. Number of Plastics Units.

\begin{tabular}{ll} 
& Number of Plastic Units \\
\hline Injection & 3,500 \\
\hline Blow & 1,000 \\
\hline Extrusion & 300 \\
\hline Wooven & 100 \\
\hline Packaging & 1,000 \\
\hline Others & 600
\end{tabular}

Source: Chaudhry, 2018. 
In addition, with, provinces-wise existence of respective plastics units is being exhibited in the following figure. According to this chart, 60 percent of plastics units are existed in Punjab while, 30 percent, 7 percent and 3 percent in Sindh, Khyber Pakhtunkhwa and Balochistan respectively (Chaudhry, 2018). Although, plastics is being

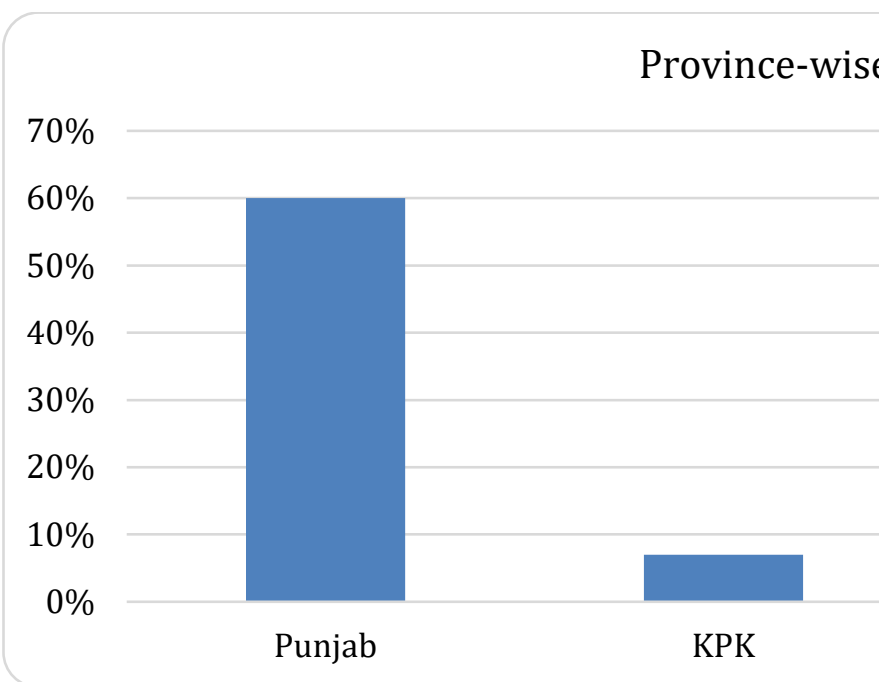

Figure 2. Province Wise Plastics Units.

Source: (Chaudhry, 2018).

\section{Pakistani Import of Man-made Staple Fibres from China}

Pakistan imports man-made staple fibers up to the worth of $\$ 576.74$ million from China. Such man-made staple fabric is being used not only in textile industries located in Wazirabad, Lahore, Gujranwala, Sialkot, Faisalabad and Sahiwal but also consume by the people at their homes. Therefore, man-mad staple fabric has lot of demand in all over the Pakistan while, its trade is being continued by road and by air. However, railway linkage will grow this trade faster (Trading-Economics, Pakistan Imports from China of Manmade..., 2017).

\section{Pakistani Import of Vehicles from China}

Although, Pakistan do not import vehicles in complete form from China, but part-wise imports have highest graph. There are hundreds of motorcycles manufacturing plants in Pakistan but all of them are importing motorcycles' part from China (Bansar, 2019).Same is the case with car industry. Although, Pakistan assembles cars from other countries, but the business of their parts has been continued from China (Bansar, 2019).Moreover, this trade is continued by road imported from China to Pakistan via sea and air routes but if there will be functional railway track between Kashgar and Havailian, all the respective trade would be converted at railway network because it would be able to provide cheapest, safe, quality and quick facilities to Chinese and Pakistani industries (Chaudhry, 2018). or by air. However, respective trade will be so increase if there will be functional railway link between China and Pakistan (Bansar, 2019).

\section{Pakistani Import of Fertilizers from China}

According to "Trading Economics", 56percent of fertilizers was imported from China to Pakistan whereas; consumption of respective fertilizers has been observed in entire agricultural land of the around Pakistan. However, the major firms which are importing fertilizers from China are existed in Lahore, Multan, Rahimyar Khan, Sadiqabad, Hyderabad, Dera Ghazi Khan, Sargodha, Gujranwala, Mardan and Sahiwal. All the respective cities are also associated with Pakistan Railways. But the problem is, respective trade is being continued by air or by road. Ratio of respective trade will be more high if there will be direct railway link between Pakistan and China (Trading-Economics, Pakistan Imports of Fertilizers, 2017).

\section{SOCIO-ECONOMIC IMPACTS OF PAK-CHINA RAILWAY CONNECTIVITY UPON THE PEOPLE OF PAKISTAN}

There are different surveys that count socio-economic impacts of Pak-China Railway Connectivity upon the people of Pakistan. This portion of the study categorizes results of respective surveys in the respective manners.

- Impacts on Home-Construction Trend.

- Impacts on Living Style

- Impacts on Food Business

- Impacts on Dress Designing Trends

- Impacts on Business Language

- Impacts on Religion-based Economy

- Impacts on cross-cultural economic-orientated marriage

- Impacts on Small Industries

- Impacts on Medium Industries

- Impacts on Large Industries (Asim, 2021).

So, firstly, this study has to analyze impacts of "PakChina Railway Connectivity" on home-construction trends.

\section{Impacts on Home-Construction Trends}

As Pak-China Railway Connectivity is not onlygenerating 
lot of opportunities for mutual understandings between Pakistani and Chinese population but it is also going to affect home-construction trends. Although, hundreds of homes have been constructed on Chinese traditional architectural designs along Karakoram Highway in Gilgit-Baltistan but, railway connectivity will shift this trend in all over the Pakistan (Asim, 2021).
According to the survey organized by " $M$ \& A Consultants", it was investigated in 2018 that why Pakistani people like to follow Chinese traditional architectural designs for their home construction (Yousafzai, 2018). Results of this survey are mentioned in Figure no. 3.

\section{Impacts on Home-Construction Trends}



Figure 3. Impacts on Home-Construction Trends.

Source: (Yousafzai, 2018).

According to this survey, among 100 people from ten different cities of Pakistan.

- 92percent says that Chinese Trend for homeconstruction is suitable for weather conditions in mountanious areas (Yousafzai, 2018).

- 73percent argues that Chinese traditional homeconstruction is attractive and ideal (Yousafzai, 2018).

- 23percent illustrates that Chinese traditional homeconstruction is cheapest for constructing new home (Yousafzai, 2018).

- 69percent expresses that Chinese-styled home construction facilitates to come close with Chinese people (Yousafzai, 2018).

On the other hand, this trend facilitates different economic sectors in Pakistan too. According to the survey managed by "Belt and Road Developers" during 2018, it is estimated that;

- More than 10 million labors will get homeconstruction jobs (Naaz, 2018).
- More than 0.09 million students will come towards field of architectural designing, and they will also adopt this field as profession (Naaz, 2018).

- More than 12.5 million people will come close to Chinese people for their business interests (Naaz, 2018).

- More than 01 million are expected to visit China for learn about Chinese home-construction trends (Naaz, 2018).

\section{Impacts on Living Styles}

Living styles comprise on "how to live" or, simple means, "lifestyle". Although, Pakistan and China have no railway link right now, but CPEC-corporation and by-road affiliation of both countries has promoted Chinese historical lifestyle; called SIHEYUAN in all over the Pakistan (especially in Khyber Pakhtunkhwa, GilgitBaltistan, Azad Kashmir and somewhat Islamabad Capital Territory) (Asim, 2021).Siheyuan is basically an historical residential living style which was and is commonly found in entire China (currently famous in rural areas of Shanxi and Beijing). Siheyuan not only 
covers lifestyle but also covers palaces, business places, government institutions' buildings and monasteries. Siheyuan is liked by both; single family system and joint family system (Asim, 2021). Promotion of Siheyuan is facilitating several industries and economic sectors in Pakistan. Some of them are as follows;

- Wood Art and Work

- Interior Decor of Home

- Furniture Art
- Doors and Windows Art

- Bedroom Fashions

- Chinese paintings

- Electrical (including lighting, lamps etc.) industry

- Kitchenwares (Asim, 2021)

In addition, with, according to the survey, organized by "Belt and Road Developers" during 2018 in GilgitBaltistan and Khyber Pakhtunkhwa, trends for adopting Chinese lifestyle are counted in Figure no. 4.

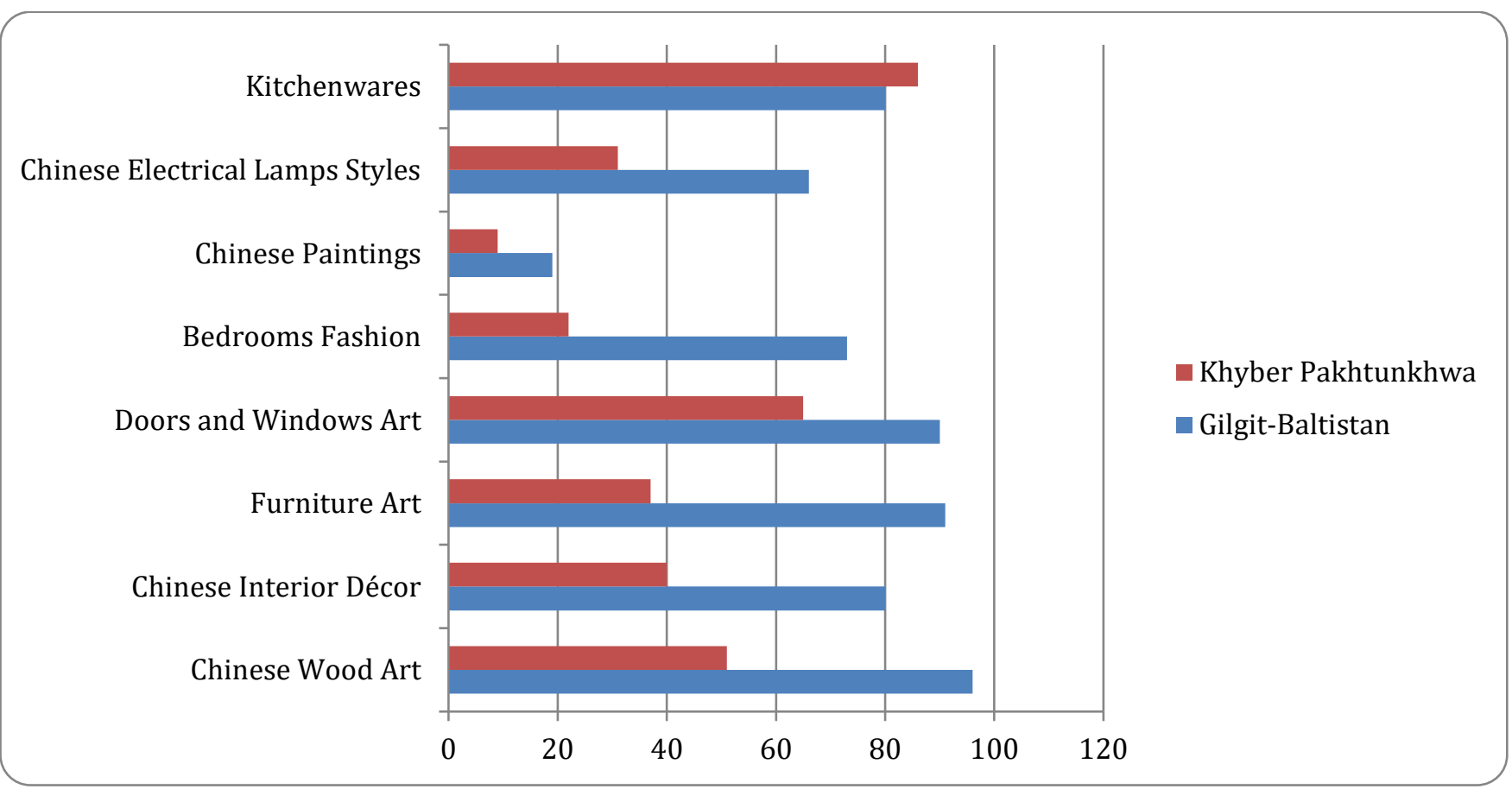

Figure 4. Impacts of CPEC regime on living styles.

Source: (BRD, 2018).

According to this chart

- 86percent people in Khyber Pakhtunkhwa and 80percent people in Gilgit-Baltistan prefer Chinesestyled kitchenwares (BRD, 2018).

- 31percent people in Khyber Pakhtunkhwa and 66percent people in Gilgit-Baltistan prefer Chinesestyled electric lamps (BRD, 2018).

- 09percent people in Khyber Pakhtunkhwa and 19percent people in Gilgit-Baltistan like Chinese paintings (BRD, 2018). Moreover, 22percent people in Khyber Pakhtunkhwa and 73percent people in Gilgit-Baltistan prefer Chinese-styled bedroom fashion (BRD, 2018).

- 65percent people in Khyber Pakhtunkhwa and 90percent people in Gilgit-Baltistan prefer Chinese- styled doors and windows art (BRD, 2018).

- 37percent people in Khyber Pakhtunkhwa and 91percent people in Gilgit-Baltistan prefer Chinesestyled furniture art (BRD, 2018).

- 40percent people in Khyber Pakhtunkhwa and 80percent people in Gilgit-Baltistan prefer Chinesestyled interior decor (BRD, 2018) and 51percent people in Khyber Pakhtunkhwa and 96percent people in Gilgit-Baltistan prefer Chinese-styled wood art (BRD, 2018).

\section{Impacts on Food Business}

During the $21^{\text {st }}$ century, it is being highly observed that the people of Pakistan are going to like Chinese cuisines. It is just because Chinese cuisine is healthy in nature. Several hotels serving Chinese cuisines have been 
opened in all over Pakistan; especially in Islamabad, Rawalpindi, Peshawar, Lahore, Multan, Bahawalpur, Karachi and Hyderabad. Moreover, hundreds of hotels serving Chinese cuisines are located around Karakoram Highway from Sost Port to Havailian and Hassan Abdal (Hussain, 2021).

Moreover, under CPEC scenario, wherever Chinese labor is working throughout the Pakistan, local hotel industry is also offering Chinese cousins for attracting Chinese labor towards them. Similarly, an amalgamation of SinoPak culture has facilitated Pakistani nation to come close towards Chinese food and Chinese cuisines (Hussain, 2021). In a survey, organized by the students of Food and Nutrition Department, University of Lahore in 2018, when people were asked by the love or prefer Chinese food, what they replied are mentioned in Figure no. 5.

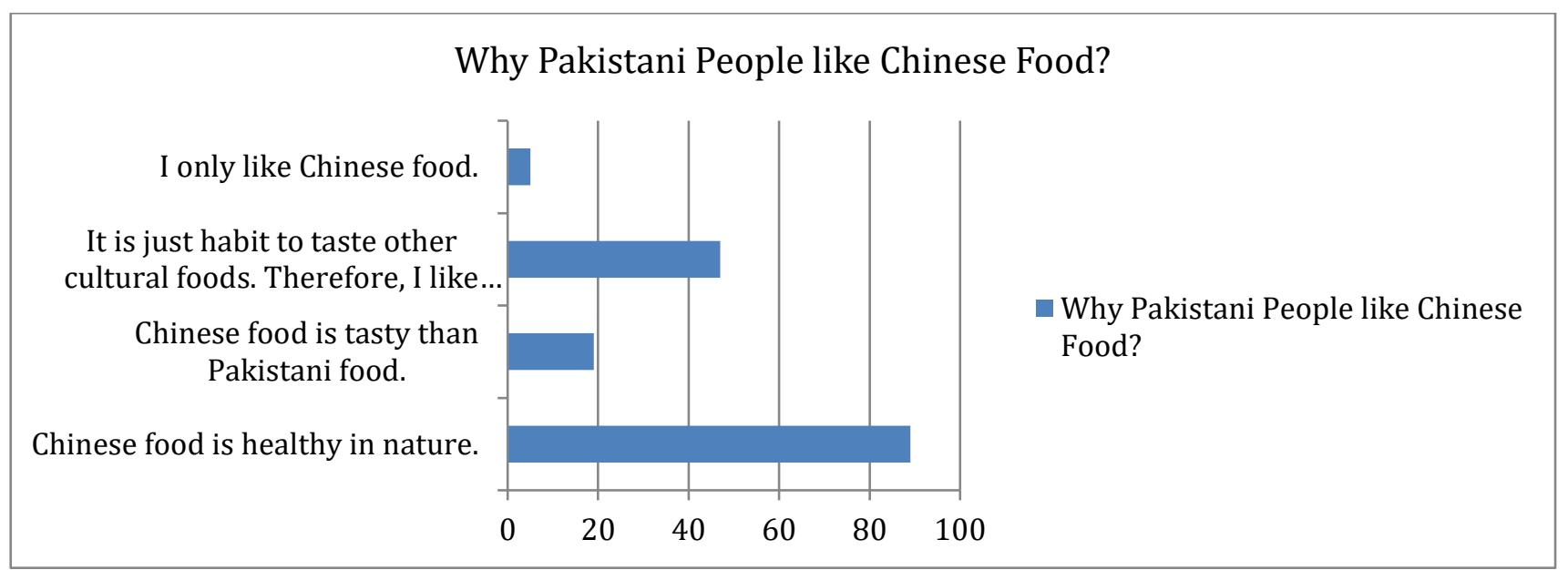

Figure 5. Why Pakistani People like Chinese Food?

Source:(Saeed, 2021).

As per the results of this survey, it is examined that,

- 89percent people argue that Chinese food is healthy in nature (Saeed, 2021).

- 19percent peope say that Chinese food is tasty than Pakistani food (Saeed, 2021).

- 47percent people express that It is just their habit to taste other cultural foods. Therefore, they like Chinese food too (Saeed, 2021).

- 05percent people say that they only like Chinese food (Saeed, 2021).

In addition, with, during the same survey, it is also investigated that which Chinese food Pakistani people like the most. According to the results, it is examined that, along with Chinese noodles and Chinese rice, people of Pakistan Chinese soybean products, Chinese desserts and snacks, Chinese sausages and Chinese soups (Saeed, 2021). Moreover, it is also observed that, in Chinese desserts, Pakistani people prefer the following desserts very much;

"Annin tofu, Banana roll, Black sesame roll, Black sesame soup, Chao hongguo, Coconut bar, Crystal cake, Custard tart, Cut cake, Douhua, Dragon's beard candy, Egg tart, Egg tong sui, Eggies, Eight treasure congee, Fried ice cream, Funing big cake, Ginger milk curd, Grass jelly, Guilinggao, Hasma, Huangqiao sesame cake, Jiuniang, JingBaJian, Kai kouxiao, Ligao Tang, Lotus seed paste, Mahua, Mango pudding, Mi sandao, Mooncake, Nailao, Niangao, Nuomici, Orange jelly candy, Pandan cake, Put chai ko, Red bean cake, Red bean soup, Red tortoise cake, Rice pudding, Red bean bun, Sachima, Song gao, Sugar painting, Sweet potato soup, Sweetheart cake, Tanghulu, Tangyuan, Tapioca pudding, Taro puree, Tong sui, White Rabbit Creamy Candy, White sugar sponge cake and Xi gualao" (Saeed, 2021).

Similarly, during asking from hotels serving Chinese cuisines in Pakistan, it is found that Pakistani people prefer following Chinese soups very much;

"Bakkut the, Banmian, Beef noodle soup, Black sesame soup, Boiled mutton soup, Cantonese seafood soup, Carp soup, Chicken soup, Corn crab soup, Egg tong sui, Fish and mustard leaf soup, Fish head soup, Geng, Hot and sour soup, Hulatang, HupTul Woo, Jiuniang, Lettuce soup, Liver soup, Lotus seed and pork tripe soup, Lung fung soup, Mung bean soup, Noodle soup, Nam ngiao, Nangchang Jar soup, Oxtail soup, Pigeon soup, Red bean soup, Sago soup, Shark fin soup, Silkie soup, Stewed 
chicken soup, Sweet potato soup, Tian mo, Tomato and egg soup, Tong sui, Turtle soup, Winter melon spare rib soup, Wonton noodle, Xidoufen and Yong Tau Foo" (Saeed, 2021).

Moreover, it is expected that trend for liking or preferring Chinese food will be more increased in case of direct railway link building. As railway will provide rapid movement between Pakistan and Chinese, it is assumed that huge number of hotels would be established around the locality of railway stations from Khunjerab to Gwadar which will offer Chinese cuisines(Hussain, 2021).

\section{Impacts on Dress Designing Trends}

There are three sorts of Chinese dresses which are being popular in Pakistan in recent days. These are;

- Hanfu (this is the historical clothing among Chinese Han people) (Asim, 2021).

- Cheongsam (this is also called Qipao. This is basically aone-piece body-hugging dress for women) (Asim, 2021)

- Changpao (this dress is specifically for men, consists upon one body-covering piece) (Asim, 2021)

Moreover, Chinese famous brand; MiniSo has opened its two franchizes in Islamabad during September 2017 while, till the end of 2017, it had nine ore stores throughout the Pakistan with generating \$1.5 million revenue (Trending.PK, 2018). Inaddition, with, several shopkeepers in Gilgit-Baltistan around the Karakoram Highway are saling Chinese traditional cloths just for attracting local and international tourists while, it is expected that Pak-China railway connectivity will facilitate this trend more than now (Saeed, 2021).

\section{Impacts on Business Language}

Since the inauguration of CPEC, Pakistani people; especially students have become keen for learning Chinese language. It is not only because they are seeking jobs in CPEC related industries and fields, but they also want to initiate business with Chinese markets and Chinese traders (Saeed, 2021).For this purpose, hundreds of Chinese language learning institutes have been established in all over Pakistan. Some are running by Pakistani teachers while, some are running by Chinese teachers too. Moreover, Government of Punjab has also initiated several scholarship programs for the students of Punjab Province regarding sending them to China for learning Chinese language (Asim, 2021).Similarly, National University of Modern Languages Islamabad has also initiated Chinese language learning program where students are being enrolled for learning this language. However, majority of enrolled students are belonged to Khyber Pakhtunkhwa and Gilgit-Baltistan (Asim, 2021). A survey which was conducted by the students at National University of Modern Languages Islamabad during 2016 which basic aim was to find the reason why students are being enrolled in the respective university for learning Chinese language, the results show in Figure no. 6 that;

It is my hobby to learn International languages. Therefore, I am learning Chinese langauge.

I want to import business products from China.

I want to initiate my own business connecting with Chinese markets.

Chinese langauge will be international language in near future.



- Khyber Pakhtunkhwa n Gilgit-Baltistan

Figure 6. Impacts of Chinese language on marketing and business environment. Source: (Adam \& Saeed, 2016). 
According to this survey, it is examined that,

- 87percent students in Khyber Pakhtunkhwa and 63percent students in Gilgit-Baltistan learn Chinese langauge because they feel that Chinese langauge will be international language in near future (Adam \& Saeed, 2016).

- 72percent students in Khyber Pakhtunkhwa and 92percent students in Gilgit-Baltistan learn Chinese langauge because they want to initiate my own business connecting with Chinese markets (Adam \& Saeed, 2016).

- 54percent students in Khyber Pakhtunkhwa and 70percent students in Gilgit-Baltistan learn Chinese langauge because they want to import business products from China (Adam \& Saeed, 2016).

- 38percent students in Khyber Pakhtunkhwa and $11 \%$ students in Gilgit-Baltistan learn Chinese langauge because It is their hobby to learn International languages. Therefore, they are learning Chinese langauge (Adam \& Saeed, 2016).

However, Pak-China railway connectivity will also motivate local shopkeepers and businessmen to learn Chinese langauge; especially those who have their business around the locality of railway stations. Such people will be forced to learn Chinese language when they will observe rapid movement of Chinese people in their localities whereas; rail link will also facilitate them to connect with Chinese markets too. Therefore, to learn Chinese language will be essential for them in near future (Asim, 2021).

\section{Impacts on Religion-based Economy}

Contemporarily, China has become a biggest manufacturer for prayer beads. As demography of Pakistan consists upon Muslims (belong to Sunni, Shia and Ismaili sects), Hindus, Sikhs, Christians and somewhat Buddhists, China is exporting a large capacity of prayer beads (related to respective religions and sects) to Pakistan (Asim, 2021).

Although, there is state-atheism officially in China, but Government of China has recognized five religions within the state. These religions are Buddhism, Confucianism, Taoism, Islam and Christianity whereas; sects among respective religious within the China are as follows;

- Within Buddhism, sects within China are Chinese Buddhism, Tibetan Buddhism, Theravada Buddhism, Vajrayana Buddhism and Japanese Buddhism whereas; within Japanese Buddhism, there are two more sub-sects. These are Shin Buddhism and Nichiren Buddhism (Asim, 2021).

- Within Christianity, there are Catholicism and Protestantism in China (Asim, 2021).

- Within Islam, there are followers of Sunni sect and Ismaili sect of Islam (Asim, 2021).

- Within Taoism, there are two sorts of followers. One sort of followers is following Vernacular ritual mastery traditions while, other sort of followers is following Chinese shamanic traditions (Asim, 2021).

In the respective scenario, question is usually raised how China has become biggest manufacturer and exporter of religious breads. Answer to this question is based upon the principles of "political economy". Chinese industry of religious breads has only concern with financial benefits. And, therefore, China has become manufacturer and exporter of religious breads with following the myths, trends and believes of different sects and religions around the world. Same is the case with Pakistan. China is exporting religious breads in Pakistan as per the requirements of Pakistani people (Muslim, Christians, Sikhs and Buddhists). Moreover, this trade can also be increased if there will be functional Sino-Pakistan railway link (Saeed, 2021).

\section{Impacts on Cross-Cultural Economic-Orientated Marriages}

As business-based and education-based co-operation between Pakistan and China is increasing day by day, this trend is also encouraging marriages between Pakistanis and Chinese people. According to "M \& A Consultants", it is recorded that, among 100 female Pakistan students staying in China for higher education, more than 40 female students have been associated with their Chinese partners. Similarly, among 100 male Pakistani students, more than 25 students have been associated with Chinese female partners (M\&A, 2017).Similarly, among 100 Pakistani businessmen who frequently visit China for their business purposes, more than 10 businessmen have married with Chinese partner while, it is also investigated that among 100 Chinese businessmen and employees who frequently visit Pakistan, more than 05 among them have been associated with Pakistani partner (M\&A, 2017).

Now, for finding the reasons why Pakistanis prefer to get marriage with Chinese partner, it is observed by "M \& A Consultants" which are mentioned in Figure no. 7. 


\section{Why Pakistanis like Cross-Cultural Marriages with Chinese?}

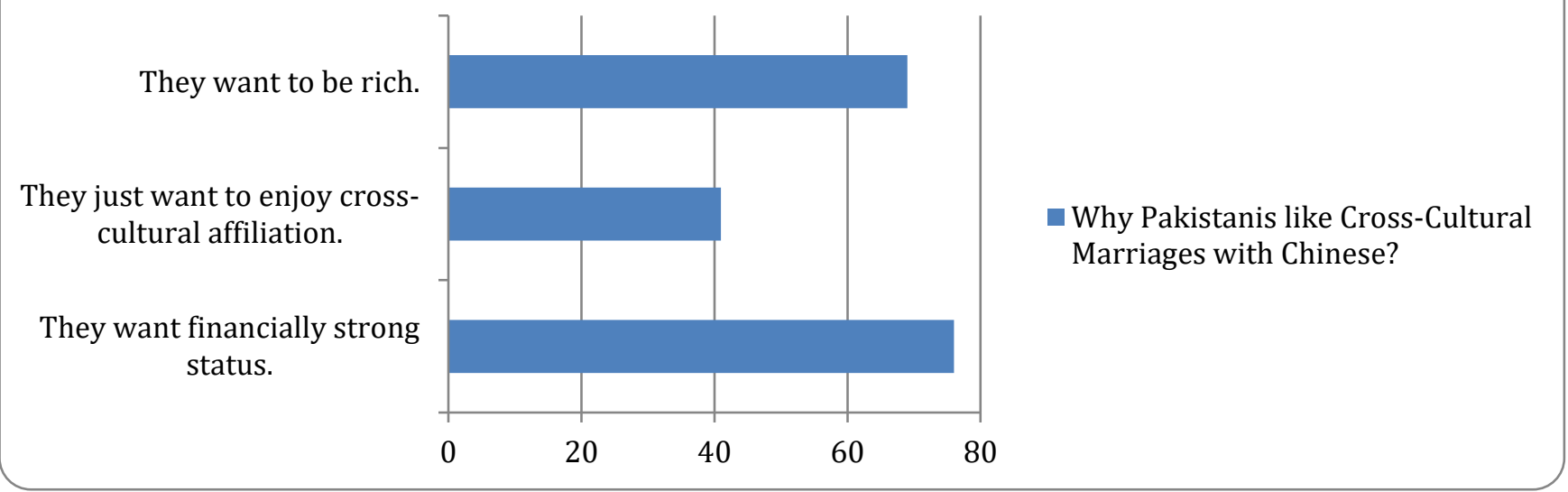

Figure 7. Why Pakistanis like Cross-Cultural Marriages with Chinese?

Source: (M\&A, 2017).

According to this survey,

- 76percent says that they want financially strong status (M\&A, 2017).

- 41percent illustrates that they just want to enjoy cross-cultural affiliation (M\&A, 2017).

- 69percent expresses that they want to be rich (M\&A, 2017).

\section{Impacts on Small Industries}

Pak-China railway connectivity under CPEC provides several opportunities to small industries in all over the Pakistan (Saeed, 2021). According to the mutual report, prepared by Pakistan-China Institute and China Radio International;Pak-China railway connectivity will facilitate 90 percent non-agricultural labor of China and Pakistan regarding traveling in between both countries for earning (Editor, 2018).

- GDP would be grown up to the 30percent(Editor, 2018).

- Small industries would become able to contribute 25percent in the exports (Editor, 2018).

- State of Pakistan would be able to generate $\$ 60$ million revenue per fiscal year (Editor, 2018)

- Small Industries will connect with Chinese markets and Chinese industries via 37 Special Economic Zones throughout the Pakistan (Editor, 2018).

- Because of 70percent agricultural land, rural areas of Pakistan would become biggest agri-enterprises (Editor, 2018).

\section{Impacts on Medium Industries}

According to the mutual report, prepared by PakistanChina Institute and China Radio International;Pakistan has established Small and Medium Enterprises Development Authority (SMEDA) in 1998 which aim was to facilitate small and medium enterprises (Editor, 2018).

- Now, under the CPEC scenario, both countries have committed to play their role in strengthening SMEDA's agenda (Editor, 2018).

- Now, target has been set for SMEDA to link small and medium industries throughout the Pakistan to Special Economic Zones (SEZs) that will further link with Chinese markets (Editor, 2018).

\section{Impacts on Large Industries}

According to the mutual report, prepared by PakistanChina Institute and China Radio International;

- Pak-China Railway Connectivity will enhance industrial growth rate in Pakistan up to 03 to 04 percent (Saeed, 2021).

- Rapid transportation between Pakistan and China will reshape industrial sector in Pakistan (Saeed, 2021).

- Pak-China railway connectivity will save $\$ 62$ billion annual expenses of Pakistan industrial sector which is being consume on slowest longest route via Karakoram Highway (Saeed, 2021).

- There will be direct relationship between Chinese and Pakistani industries.

- Industries of both countries will be in position to exchange skilled human resource via rapid train service (Saeed, 2021).

- Cargo trains between both countries will facilitate industrial growth not only in Gilgit-Baltistan, Khyber 
Pakhtunkhwa and Balochistan provinces of Pakistan but also in Xinjiang and Tibet regions of China(Zaheer, 2021).

\section{CONCLUSION}

It has been concluded that industrial linkage with China affecting socio-economic life of Pakistani people in distinct styles. As Chinese imports are rapidly utilizing within the social spheres of Pakistan, this trend is also affecting human nature where newly built Pak-China culture is also installing new Pak-China society that may have common architectural designs, lifestyle, food stuff, dressing, routine economy, cross-cultural associations, marriages, and interlinked business activities (Asim, 2021). However, it seems to be one-way traffic where Pakistani society is more influencing by Chinese imports whereas; Pakistani exports towards China are comparatively much less in worth. Therefore, critics usually declare this trend as the Chinanization of Pakistan.

\section{REFERENCES}

Adam, Z., \& Saeed, T. (2016). Survey in NUML for Chinanization of Pakistani Culture. Islamabad, Pakistan.

Asim, D. M. (2021, March 07). Socio-Economic Impacts of CPEC in Pakitan. (T. Saeed, Interviewer)

Bansar. (2019). How to Import from China to Pakistan: The Complete Guide in 2019. Retrieved February 14, 2019, from Bansar: https://www.bansarchina.com/how-to-importfrom-china-to-pakistan/

BRD. (2018). Impacts of CPEC on Pakistanis Lifestyle. Islamabad and Lahore, Pakistan: Belt and Road Developers Islamabad.

Chaudhry, F. A. (2018, December). An Overview of Pakistan's Plastics Industry. Retrieved January 21, 2019, from Plastemart.com: http://atozplastics.com/upload/literature/pakist an.asp

Editor. (2018, April 16). The CPEC 'edge' for the SMEs. Retrieved March 03, 2019, from CPEC Info: http://www.cpecinfo.com/news/the-cpec-edgefor-the-smes/NTEyOA==

Hussain, D. A. (2021, February 14). Impacts of Chinese Investment on Daily Routin Life of Common People in Pakistan. (T. Saeed, Interviewer)

M\&A. (2017). Survey on Chinese Socio-Economic Impacts in Punjab, Sindh, KPK and Balochistan. Peshawar and Quetta, Pakistan: M \& A Consultants Islamabad.

Naaz, N. (2018, August). Impacts on Chinese-Styled Homes Construction on Economy of Pakistan. Retrieved January 10, 2019, from Eurasian Politics:

eurasianpolitics.wordpress.com/2019/05/06/im pacts-on-chinese-styled-homes-construction-oneconomy-of-pakistan/

Saeed, T. (2021, January 30). Survey about Chinanization of Pakistan. Lahore and Islamabad, Pakistan.

Trading-Economics. (2017). Pakistan Exports of Copper and articles. Retrieved May 06, 2019, from Trading Economics:

https://tradingeconomics.com/pakistan/exports/ copper

Trading-Economics. (2017). Pakistan Exports of Cotton. Retrieved May 02, 2019, from Trading Economics: https://tradingeconomics.com/pakistan/exports/ cotton

Trading-Economics. (2017). Pakistan Exports to Afghanistan. Retrieved May 01, 2019, from Trading Economics: https://tradingeconomics.com/pakistan/exports/ afghanistan

Trading-Economics. (2017). Pakistan Exports to China of Cereals. Retrieved April 30, 2019, from Trading Economics:

https://tradingeconomics.com/pakistan/exports/ china/cereals

Trading-Economics. (2017). Pakistan Exports to China of Fish, crustaceans, molluscs, aquatics invertebrates. Retrieved May 01, 2019, from Trading Economics: https://tradingeconomics.com/pakistan/exports/ china/fish-crustaceans-molluscs-aquaticsinvertebrates

Trading-Economics. (2017). Pakistan Exports to China of Optical, photo, technical, medical apparatus. Retrieved April 29, 2019, from Trading Economics:

https://tradingeconomics.com/pakistan/exports/ china/optical-photo-technical-medical-apparatus

Trading-Economics. (2017). Pakistan Exports to China of Ores slag and ash. Retrieved January 31, 2019, from Trading Economics: https://tradingeconomics.com/pakistan/exports/ china/ores-slag-ash 
Trading-Economics. (2017). Pakistan Exports to China of Raw hides and skins (other than furskins) and leather. Retrieved May 06, 2019, from Trading Economics:

https://tradingeconomics.com/pakistan/exports/ china/raw-hides-skins-than-furskins-leather

Trading-Economics. (2017). Pakistan Exports to China of Salt, sulphur, earth, stone, plaster, lime and cement. Retrieved May 06, 2019, from Trading Economics: https://tradingeconomics.com/pakistan/exports/ china/salt-sulfur-earth-stone-plaster-lime-cement

Trading-Economics. (2017). Pakistan Exports to China. Retrieved January 01, 2019, from Trading Economics:

https://tradingeconomics.com/pakistan/exports/ china

Trading-Economics. (2017). Pakistan Exports to China. Retrieved March 19, 2019, from Trading Economics:

https://tradingeconomics.com/pakistan/exports/ china

Trading-Economics. (2017). Pakistan Imports from Afghanistan. Retrieved March 02, 2019, from Trading Economics: https://tradingeconomics.com/pakistan/imports /afghanistan

Trading-Economics. (2017). Pakistan Imports from China of Electrical, electronic equipment. Retrieved January 20, 2019, from Trading Economics: https://tradingeconomics.com/pakistan/imports /china/electrical-electronic-equipment

Trading-Economics. (2017). Pakistan Imports from China of Iron and steel. Retrieved February 24, 2019, from Trading Economics: https://tradingeconomics.com/pakistan/imports /china/iron-steel

Trading-Economics. (2017). Pakistan Imports from China of Machinery, nuclear reactors, boilers. Retrieved April 13, 2019, from Trading Economics: https://tradingeconomics.com/pakistan/imports /china/nuclear-reactors-boilers-machinery

Trading-Economics. (2017). Pakistan Imports from China of Manmade staple fibers. Retrieved April 11, 2019, from trading Economics: https://tradingeconomics.com/pakistan/imports /china/manmade-staple-fibers

Trading-Economics. (2017). Pakistan Imports from China of Organic chemicals. Retrieved May 02, 2019, from Trading Economics: https://tradingeconomics.com/pakistan/imports /china/organic-chemicals

Trading-Economics. (2017). Pakistan Imports from China. Retrieved May 07, 2019, from Trading Economics:

https://tradingeconomics.com/pakistan/imports /china

Trading-Economics. (2017). Pakistan Imports of Fertilizers. Retrieved March 10, 2019, from Trading Economics: https://tradingeconomics.com/pakistan/imports /fertilizers

Trading-Economics. (2018). China Exports to Afghanistan. Retrieved April 22, 2019, from Trading Economics: https://tradingeconomics.com/china/exports-toafghanistan

Trading-Economics. (2018). China Imports from Afghanistan. Retrieved May 02, 2019, from Trading Economics: https://tradingeconomics.com/china/importsfrom-afghanistan

Trending.PK. (2018, January 16). Famous Chinese fashion brand is aggressively expanding in Pakistan. Retrieved March 03, 2019, from Trending.PK: https://trending.pk/2018/01/famous-chinesefashion-brand-aggressively-expandingpakistan/

Yousafzai, A. A. (2018, April-May). Impacts of CPEC on Homes Industry in Pakistan. Retrieved March 23, 2019, from Eurasian Politics: https://eurasianpolitics.wordpress.com/2019/ 05/06/impacts-of-cpec-on-homes-industry-inpakistan/

Zaheer, A. (2021). China-Iran Srategic Relationship; Implication on Geopolitics of Persian Gulf. PhD thesis. Bahawalpur, Punjab, Pakistan: Department of Political Science at the Islamia University of Bahawalpur. 
Publisher's note: EScience Press remains neutral with regard to jurisdictional claims in published maps and institutional affiliations. (⿶) use, sharing, adaptation, distribution and reproduction in any medium or format, as long as you give appropriate credit to the original author(s) and the source, provide a link to the Creative Commons license and indicate if changes were made. The images or other third-party material in this article are included in the article's Creative Commons license, unless indicated otherwise in a credit line to the material. If material is not included in the article's Creative Commons license and your intended use is not permitted by statutory regulation or exceeds the permitted use, you will need to obtain permission directly from the copyright holder. To view a copy of this license, visit http://creativecommons.org/licenses/by/4.0/.

(C) The Author(s) 2021. 